\title{
Estimated glycemic index of rice increases with the release of new varieties in the middle reach of the Yangtze River
}

\author{
Min Huang ${ }^{1} \cdot$ Zhengwu Xiao $^{1} \cdot$ Liqin Hu$^{1} \cdot$ Jiana Chen $^{1} \cdot$ Fangbo Cao $^{1}$ \\ Received: 8 December 2021 / Accepted: 21 December 2021 \\ Published online: 04 January 2022 \\ (c) The Author(s) $2021 \quad$ OPEN
}

\begin{abstract}
The amylose content of newly-released rice varieties has steadily decreased in rice-growing regions in the middle reach of the Yangtze River during 2006-2021, to parallel increasing consumption of soft-textured rice with low amylose content. We estimated the glycemic index of these newly-released rice varieties and reveal a significantly increasing trend, showing a 0.3 annual increase in estimated glycemic index of new rice varieties released each year. These results highlight the need to assess the potential health risks associated with the development of soft-textured rice with low amylose rice.
\end{abstract}

Keywords Amylose content · Glycemic index · Rice

Rice is a staple food that provides about $30 \%$ of the dietary energy consumed by over $65 \%$ of the human population in China [1]. As living standards improve, the consumption of high eating quality rice-mainly soft-textured rice with low amylose content-has substantially increased in China [2]. However, it is well documented that rice with a lower amylose content is generally less resistant to digestion and has a higher glycemic index [3]. Diets with a high glycemic index are associated with increased incidence of non-communicable diseases such as type 2 diabetes and cardiovascular $[4,5]$. Thus, the development of low amylose content rice varieties may counter efforts to promote a healthy population in China, highlighting the urgent need to evaluate the change in the glycemic index of rice in China [6].

The middle reach of the Yangtze River (including Hunan, Jiangxi, and Hubei provinces) is a major rice-producing region in China that contributes to over 30\% of the total national rice production [7]. As a result of targeted breeding efforts, the amylose content of new rice varieties has experienced a steady decreasing trend in the middle reach of the Yangtze River since 2006 (Fig. 1A). Amylose content significantly decreased from $20.0 \%$ in rice varieties released during $2006-2009$ to $17.7 \%$ in those released during $2013-2015$, to $16.6 \%$ in those released during $2016-2018$, and to $15.9 \%$ in those released during 2019-2021.

Based on the linear relationship between the glycemic index and amylose content of rice plotted by Fitzgerald et al. [3], we estimated the glycemic index of rice varieties released from 2006-2021 in the middle reach of the Yangtze River (Fig. 1B). The results showed that the estimated glycemic index significantly increased from 68.3 in rice varieties released during 2006-2009 to 70.4 in those released during 2013-2015, to 71.4 in those released during 2016-2018, and to 72.0 in those released during 2019-2021. Moreover, trend analysis indicated that the estimated glycemic index of rice varieties increased in accordance with their year of release; the estimated glycemic index of rice increased by approximately 0.3 per year in newly released varieties.

Min Huang, mhuang@hunau.edu.cn | ${ }^{1}$ Rice and Product Ecophysiology, Key Laboratory of Ministry of Education for Crop Physiology and Molecular Biology, Hunan Agricultural University, Changsha 410128, China. 

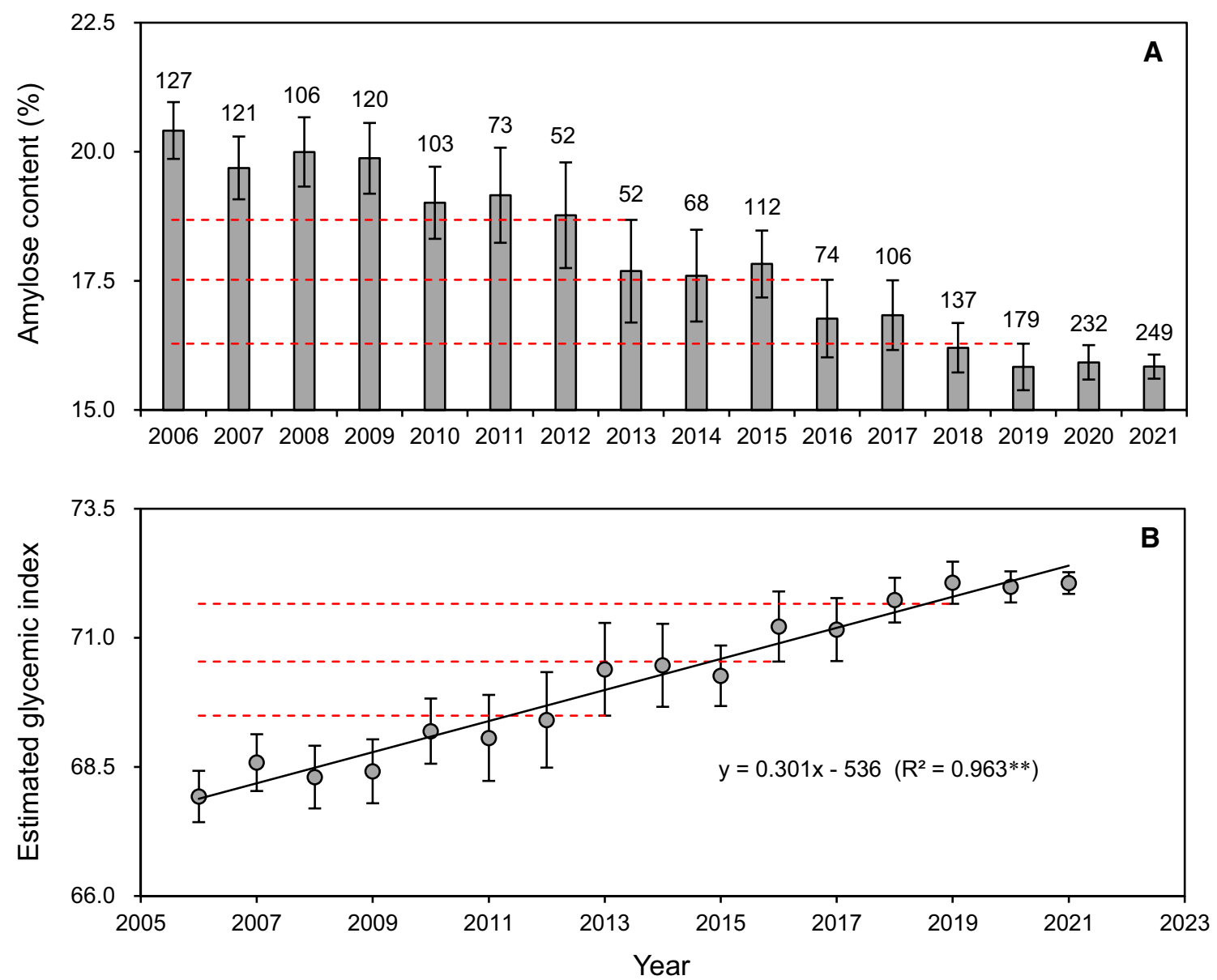

Fig. 1 Amylose content (A) and estimated glycemic index (B) of rice varieties released during 2006-2021 in the middle reach of the Yangtze River. Values on error bars are the number of varieties released per year. Data points are means, and error bars show $95 \%$ confidence intervals. Means are significantly different if their confidence intervals do not overlap, and dashed red lines are used to indicate significant differences. ** denotes significant trend at the 0.01 probability level. The data of amylose content was obtained from the China Rice Data Center (http://www.ricedata.cn/variety)

In summary, the estimated glycemic index of newly released rice varieties used in the middle reach of the Yangtze River in recent years has significantly increased as a result of the development of soft-textured rice with low amylose content in response to consumer preference. This finding can also be supported by an in vitro starch digestion assay using seven rice varieties grown in the middle reach of the Yangtze River, which showed that starch digestion rate significantly increased with decreasing amylose content (Fig. 2).

We hope the finding of this study will attract societal attention and help raise awareness of the health risks associated with the consumption of this type of rice in China and other major rice-consuming countries. We also appeal to the government to immediately initiate an interdisciplinary collaboration between crop and food scientists and the public health sector to (1) comprehensively assess the potential health risks associated with the consumption of soft-textured rice with low amylose content and (2) find feasible approaches to resolve the contradiction between rice-eating quality and unintended health risks to rice consumers. 


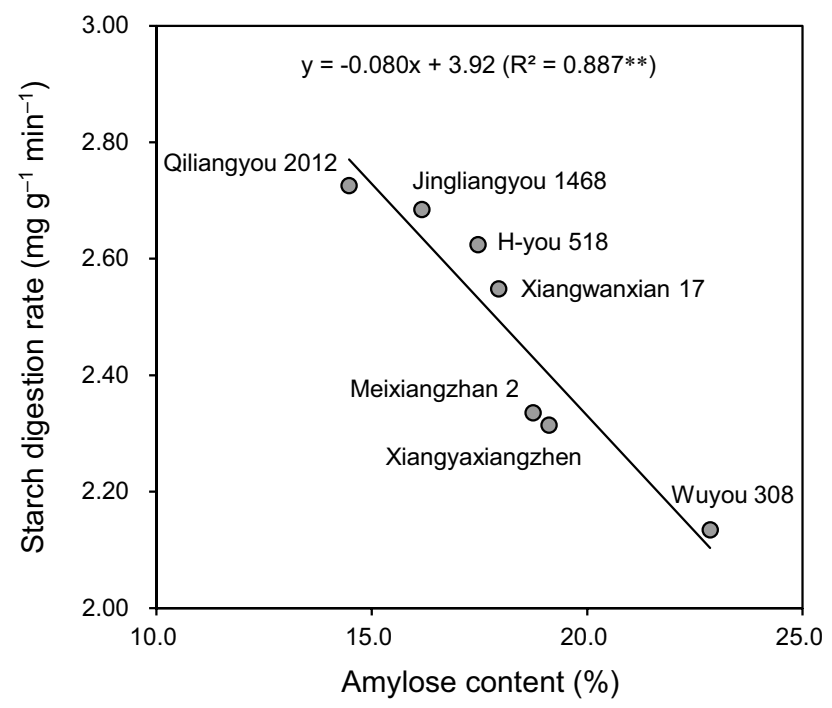

Fig. 2 The relationship between starch digestion rate (i.e., the rate of digestion of starch into glucose) and amylose content across seven rice varieties grown in the middle reach of the Yangtze River. ${ }^{* *}$ denotes significant relationship at the 0.01 probability level. The rice varieties were selected based on the amylose content representing the range of mean amylose content of rice varieties released during 2006-2021 in the middle reach of the Yangtze River. The starch digestion rate was determined by an in vitro method using a NutriScan GI20 Glycemic Index Analyser (Next Instruments, Condell Park, New South Wales, Australia) [2]

Acknowledgements This study was supported by the National K\&R Program of China (2016YFD0300509).

Authors' contributions $\mathrm{MH}$ conceived the study, analysed the data, and wrote the manuscript. ZX, LH, JC, and FC collected the data. All authors reviewed the manuscript.

Data availability The datasets generated during and analysed during the current study are available from the corresponding author on reasonable request.

\section{Declarations}

Competing interests The authors declare no competing interests.

Open Access This article is licensed under a Creative Commons Attribution 4.0 International License, which permits use, sharing, adaptation, distribution and reproduction in any medium or format, as long as you give appropriate credit to the original author(s) and the source, provide a link to the Creative Commons licence, and indicate if changes were made. The images or other third party material in this article are included in the article's Creative Commons licence, unless indicated otherwise in a credit line to the material. If material is not included in the article's Creative Commons licence and your intended use is not permitted by statutory regulation or exceeds the permitted use, you will need to obtain permission directly from the copyright holder. To view a copy of this licence, visit http://creativecommons.org/licenses/by/4.0/.

\section{References}

1. Ray DK, Mueller ND, West PC, Foley JA. Yield trends are insufficient to double global crop production by 2050. PLoS ONE. 2013;8:e66428.

2. Huang M, Li X, Hu L, Xiao Z, Chen J, Cao F. Comparing texture and digestion properties between white and brown rice of indica cultivars preferred by Chinese consumers. Sci Rep. 2021;11:19054.

3. Fitzgerald MA, Rahman S, Resurreccion AP, Concepcion J, Daygon VD, Dipti SS, Kabir KA, Klingner B, Morell MK, Bird AR. Identification of a major genetic determinant of glycemic index in rice. Rice. 2011;4:66-74.

4. Greenwood DC, Threapleton DE, Evans CEL, Cleghorn CL, Nykjaer C, Woodhead C, Burley VJ. Glycemic index, glycemic load, carbohydrates, and type 2 diabetes. Diabetes Care. 2013;36:4166-71.

5. Jenkins DJA, Dehghan M, Mente A, Bangdiwala SI, Rangarajan S, Srichaikul K, Mohan V, Avezum A, Díaz R, Rosengren A, Lanas F, LopezJaramillo P, Li W, Oguz A, Khatib R, Poirier P, Mohammadifard N, Pepe A, Alhabib KF, Chifamba J, Yusufali AH, lqbal R, Yeates K, Yusoff K, Ismail N, Teo K, Swaminathan S, Liu X, Zatońska K, Yusuf R, Yusuf S. Glycemic index, glycemic load, and cardiovascular disease and mortality. New Engl J Med. 2021;384:1312-22.

6. Huang M, Hu L. Low glycemic index: the next target for rice production in China? J Integr Agr. 2021;20:1727-9.

7. Wang Z, Wang H, Huang G. Strategy study of grain production in the middle reach of the Yangtze River. Chin Agric Sci Bull. 2018;34:158-64.

Publisher's Note Springer Nature remains neutral with regard to jurisdictional claims in published maps and institutional affiliations. 